San Jose State University

SJSU ScholarWorks

Faculty Research, Scholarly, and Creative Activity

$6-22-2018$

\title{
Making Matters Worse by Trying to Make Them Better? Exploring Vicious Circles of Decision in Hybrid Partnerships
}

\author{
Paula Ungureanu \\ University of Modena and Reggio Emilia \\ Fabiola Bertolotti \\ University of Modena and Reggio Emilia \\ Elisa Mattarelli \\ San Jose State University, elisa.mattarelli@sjsu.edu \\ Francesca Bellesia \\ University of Bologna
}

Follow this and additional works at: https://scholarworks.sjsu.edu/faculty_rsca

Part of the Business Administration, Management, and Operations Commons

\section{Recommended Citation}

Paula Ungureanu, Fabiola Bertolotti, Elisa Mattarelli, and Francesca Bellesia. "Making Matters Worse by Trying to Make Them Better? Exploring Vicious Circles of Decision in Hybrid Partnerships" Organization Studies (2018): 1331-1359. https://doi.org/10.1177/0170840618765575

This Article is brought to you for free and open access by SJSU ScholarWorks. It has been accepted for inclusion in Faculty Research, Scholarly, and Creative Activity by an authorized administrator of SJSU ScholarWorks. For more information, please contact scholarworks@sjsu.edu. 


\title{
PLEASE CITE AS:
}

Ungureanu, P., Bertolotti, F., Mattarelli, E., \& Bellesia, F. (2018). Making matters worse by trying to make them better? Exploring vicious circles of decision in hybrid partnerships. Organization Studies, 0170840618765575.

\section{Making matters worse by trying to make them better? Exploring vicious circles of decision in hybrid partnerships}

\author{
Paula Ungureanu ${ }^{1 *}$ \\ Fabiola Bertolotti ${ }^{1}$ \\ Elisa Mattarelli ${ }^{1}$ \\ ${ }^{1}$ Department of Sciences and Methods for Engineering \\ University of Modena and Reggio Emilia, Italy \\ Francesca Bellesia ${ }^{2}$ \\ ${ }^{2}$ Department of Management \\ University of Bologna, Italy \\ *Corresponding author: \\ Department of Sciences and Methods for Engineering - "DISMI" \\ University of Modena and Reggio Emilia \\ Via Amendola 2 - Pad. Morselli \\ 42122 Reggio Emilia, Italy \\ paula.ungureanu@unimore.it
}

Acknowledgements: We thank Andrew Van de Ven and Silviya Svejenova for their useful comments on a previous version of the paper and are grateful for the valuable feedbacks we received from the participants of the AOM 2016 Annual Meeting, and in particular from Kristina Lauche. This research was partially funded by INTERMECH within the project 'Economic Solidarity'. 


\title{
Making matters worse by trying to make them better? Exploring vicious circles of decision in hybrid partnerships
}

\begin{abstract}
Our research is concerned with how and why vicious circles of decision occur in hybrid partnerships. The literature has reported three types of decision dysfunctions to explain why multistakeholder collaborations take longer to dissolve than required, or produce different outcomes than the ones envisioned in the initial stages: escalation of commitment, procrastination, and indecision. However, while previous studies have focused on one dysfunction at a time, we inquire about the cases in which multiple dysfunctions coexist and interact in the same partnership. Employing multiple sources of qualitative data, we conducted a field study in a hybrid partnership in which highly differentiated organizations came together to co-create and manage a science park. We offer an in-depth account of how partners' attempts to solve a dysfunction can paradoxically lead to the accumulation of additional dysfunctions, and call this process 'vicious circle of decision'. Two intervening mechanisms are described. First, enacted solutions are conditioned by the very risk-opportunity tensions they try to solve. Second, the tendency to make solutions visible to everyone by inscribing them in material artefacts can generate unexpected consequences by which risk-opportunity tensions are renewed instead of solved. In addition to the literature on hybrid partnerships, we also contribute to the debate in organization studies about the impact of concurrent risk-opportunity tensions on the evolution of collaborations, and theorize about the role of materiality in such processes.
\end{abstract}

\section{Keywords}

hybrid partnerships, decision dysfunctions, indecision, procrastination, escalation of commitment, risk-opportunity tensions, collaborative spaces, materiality, science park, interorganizational collaborations 


\section{Introduction}

In the past 25 years interorganizational collaborative activities have become more prominent and extensive in all national and transnational sectors, often assuming hybrid forms of engagement between extremely diverse organizations such as businesses, governments, universities, hospitals, trade and professional associations, banks, NGOs, and the civil society (e.g. Gray, 1989; Bryson et al., 2006; Selsky \& Parker, 2005). Also known as 'social partnerships' (Austin \& Seitanidi, 2012a; Waddock, 1989), or ‘cross-sector partnerships’ (Googing \& Rochlin, 2000; Geddes, 2008), hybrid collaborations come to life to deal with complex social problems that exceed the scope and jurisdiction of the single partnering organizations, by building on the capabilities, resources and expertise developed by each partner in a sector of reference (see also Austin \& Seitanidi, 2012a; Geddes, 2008; Hardy \& Philips, 1998). Improving the competitiveness of a region (Linder \& Rosenau, 2000), managing urban regeneration (Pitsis et al., 2003), providing integrated healthcare or leveraging occupation rates (Huxham \& Vangen, 2000a, 2013), are some examples of problems that hybrid collaborations commonly address.

However, despite the widely recognized value and an abundance of policies in their support, several studies highlight that hybrid partnerships report ambiguous, dissatisfying or even failing outcomes (Hodge \& Greve, 2007). Studies about megaprojects - large-scale, long-lasting and high-investment projects that are usually accomplished through hybrid partnerships (Flyvbjerg et al., 2005; Van Marrewijk et al., 2008) - provide staggering results: approximately one out of ten megaprojects is on budget, one out of ten on schedule, and one out of ten fulfils promised benefits. The difficulties of these collaborations become emblematic for researchers and public opinion alike. For instance, the Parisian innovative system of personal rapid transportation called Aramis was initiated in 1987 and shut down by the local administration 17 years later, due to enormous 
project costs, the criticism of the public opinion, and the acknowledgement of an impossible purpose - i.e. making small cars run as virtual trains inside Paris (Latour, 1996).

A series of partnership dysfunctions have been highlighted to explain why hybrid partnerships may fail to produce the desired outcomes, such as escalation of commitment, procrastination, and indecision. Escalation of commitment refers to the tendency to persist and additionally invest in a course of action despite evidence of failure (Brockner, 1992; Ross \& Staw, 1986; 1993). Procrastination refers to the delay or postponement of an intended course of action which requires to sacrifice a preferred situation in the present for a future benefit (Akerlof, 1991; Harris \& Sutton, 1983). Indecision refers to the perpetual making and remaking of decisions that creates a state of chronic collective ambivalence in the partnership (see Denis et al., 2011). These dysfunctions are generally considered alternative explanations for faulty decision processes. However, paradoxically, while studies explain one dysfunction at a time, their accounts of hybrid partnership failure report a plurality of dysfunctional processes which may occur simultaneously (i.e. Staw \& Ross, 1987; Van Marrewijk et al., 2008) or in sequence (Drummond, 2017; Flyvbjerg et al., 2005; Ross \& Staw, 1993; McNamara et al., 2002). To investigate these possibilities, we adopt a processbased perspective which draws on an actor-network perspective.

Differently from previous studies that have studied one decision dysfunction at a time and tried to identify faulty mechanisms attributable to each dysfunction, the actor-network perspective assumes that decision dysfunctions are not localized; they emerge out of complex chains of interactions between specific interests that animate a network's events, practices, and material artefacts. In the case of a hybrid partnership, as each actor-partner tries to achieve interests at hand inside a common frame, those very interests transform each other and become displaced, potentially pushing the partnership towards new and unpredictable directions (Callon, 1999; 
Latour, 1996; 2005). We thus adopt the actor-network perspective to investigate how decision dysfunctions coexist and interact in hybrid partnerships and with what consequences for how a partnership moves ahead (displacements, transformations, etc.).

To answer this research question, we conducted a qualitative study about a public-private collaboration that set up a science park to encourage collaborative innovation projects in a highly industrialized European region. Our findings show that decision dysfunctions accumulate and interact over time because of concurrent opportunity-risk tensions that keep partners oscillating between tendencies to invest (opportunity seeking) and impulses to disinvest (risk aversion). Each risk-opportunity tension generates a decisional dysfunction that partners try to actively solve. Paradoxically, the proposed solutions are significantly conditioned by the very risk-opportunity tension that partners try to solve - becoming what we called 'halfway solutions': situations that linger individuals' decision-making ability by bounding them to both desired (i.e., opportunity) and feared (i.e., threats) scenarios, without integration or progression. We show that the inscription of halfway solutions in material artefacts not only augments existing dysfunctions but also adds up new ones, in a self-perpetuating vicious circle.

Our insights offer several contributions. First, we theorize about the vicious circles by which decision dysfunctions accumulate in hybrid partnerships and push them off course. We move towards more dynamic explanations of the interplay between impasses, iterative solution attempts, and their intended vs unintended consequences. Second, we bring a contribution to the organizational literature on opportunity-risk framing. We contrast established claims in paradox studies about the beneficial role (i.e. generative and progressive) of oscillating between opportunities and risks during collaboration. Third, we bring to the fore the important but still 
underexplored role of material inscription in vicious circles of collaboration arguing about its connection to actors' concerns about future legitimation (i.e. prospected visibility).

\section{Dysfunctions in hybrid partnerships}

Decision dysfunctions are emergent processes by which hybrid partnerships that navigate frames of negative or controversial opinions, in particular in relation to inefficient utilization of resources or to limited ability to reach the partnership goals, significantly alter their expected trajectories in the attempt to survive throughout and beyond their natural lifecycle (see Flyvbjerg et al., 2005; Pistis et al., 2003; Van Marrewijk et al., 2008). The most frequently cited dysfunctions have been escalation of commitment and procrastination, and, more recently, indecision in collaboration networks. As follows, a brief description of each dysfunction is provided.

\section{Escalation of commitment}

According to many well-established social psychology studies, individuals tend to reinforce commitment to a failing course of action, usually by generating sufficient resources of capital and legitimacy to offset evident proofs of negative performance (Brockner \& Rubin, 1985; Staw, 1976). Numerous explanations for why people engage in escalation behaviour have been offered, such as the need to save face (Brockner \& Rubin, 1985; Staw, 1976), the perception of sunk costs and the need to switch to a gains frame (Arkes \& Blumer, 1985; Brockner, 1992), as well as the compelling need to bring things to completion (Conlon \& Garland, 1993).

A limited number of contributions have brought evidence that organizations, like individuals, also have problems in terminating commitments because they get trapped in sunk costs and desire to bring projects to the initially envisioned state (see Sleesman et al., 2012 for a review). For instance, Ross and Staw $(1986,1993)$ have documented the escalation of commitment in the 1966 project of the U.S. Department of Energy to build and operate the Shoreham Nuclear Power Plant. 
The authors describe a pattern of escalation of project costs by more than 60 times over a period of 23 years, including countless rounds of negotiations, adjustments to environmental changes and unexpected project decisions, which culminated with a final decision to terminate the project. Studies at organizational and inter-organizational level assume that escalation can be prevented or fought against with the help of a strong leadership basis, rational planning, and careful evaluation of risks and opportunities. For instance, common suggestions include counterbalancing initial enthusiasm by being vigilant, beginning a partnership with doubts, and setting non-negotiable limits (see Drummond, 2017; Flyvbjerg et al., 2005).

\section{Procrastination}

Procrastination refers to the delay or postponement of an intended course of action that implies some sacrifice in the short term (Akerlof, 1991; Harris \& Sutton, 1983). The seminal study by Ackerlof (1991) defines procrastination as delay both in initiating intended projects and in terminating them. Most explanations for procrastination at the individual level refer to a propensity for hedonism, extrinsic motivation, and immediate gratification (for a review, see Steel, 2007). Rare studies at the organizational level see procrastination as an avoidant-defensive strategy by which managers try to cope with stressful organizational events (Hodgkinson \& Wright, 2002). The literature on megaprojects suggests that organizations engaged in complex partnerships might postpone those courses of action that are less straightforward or that they feel less prepared to deal with in the present, such as clarifying broad or ambiguous project goals, generating agreement or solving conflicts (Flyvbjerg et al., 2005; Marrewijk et al., 2008;). Yet, while these studies usually indicate making goals more proximal, irreversible, or cognitively appealing as solutions to prevent procrastination (Harris \& Sutton, 1983; Steel, 2007), they rarely explain when and how procrastination persists through time. 


\section{Indecision}

Indecision has been defined as a state of chronic ambivalence triggered by perpetual reconsideration of decisions (Denis et al., 2011; Raisin, 2006). Unlike procrastination that implies delaying an intended action, indecision is a consequence of not knowing what the best course of action is. Accordingly, individuals become unable to properly evaluate the opportunities and risks of each alternative and thus remain caught in between alternative courses of action (Raisin, 2006). A limited number of studies have suggested that hybrid partnerships are particularly prone to indecision (see Denis et al., 2011). In the literature on interorganizational collaboration, Huxham (1996) has referred to this phenomenon as collaboration inertia, i.e. the tendency to slow down or stop pursuing what the partnership was established for. In their study on networks of indecision, Denis and colleagues (2011) illustrated how the configuration of a group of teaching hospitals was continually made, unmade and remade, as partners alternated between high conflict and courses of action that temporarily lowered it. Heterogeneous and political interests, uncertainty about available resources, and long-term horizons have been invoked to explain indecision in interorganizational collaborations (see Huxham, 1996). Among the suggestions for unfreezing indecision, these studies propose simplifying alternatives, making commitments to concrete courses of action, and bringing in negotiators (Denis et al., 2011; Klijn, 2008).

\section{The interplay of dysfunctions in hybrid partnerships' lifecycle: towards a new perspective}

Escalation, procrastination and indecision have been treated as alternative explanations of failure in hybrid collaborations, but the possibility that they interact over time within the same partnership has been rarely contemplated. To give some examples, although Ross and Staw's (1986, 1993) seminal studies on Expo 1986 and the Shoreham Power Plant focus on partners' escalation of budget and timing, their account can also be read as an interplay between escalation 
and procrastination. For instance, in addition to increased investments (escalation), authors also mention instances in which stakeholders postpone further project investments or hesitate to make public communications (procrastination). Although these instances are not focal in Ross and Staw's accounts, they contribute significantly to explaining how actors were able to escalate commitment for such extended periods of time. Similarly, a careful reading of the account provided by Denis and colleagues (2011) indicates that indecision does not imply just waiting for better times to bring a project to life, but also making desperate attempts to force project decisions into being (escalation). Based on these arguments, we suggest that escalation, procrastination and indecision mechanisms might have more explanatory power about hybrid partnership failure when considered jointly and dynamically.

To this purpose, we propose a shift from the study of single dysfunctions to the social mechanisms by which collective decisions become dysfunctional in a partnership. According to Marrawijk and colleagues (2008), the dysfunction perspective is often over-deterministic, accusing partners of lacking good-will, yet acknowledging that rarely is there a truth about multi-party collaborations. In a book dedicated to the Aramis case, Latour (1996) uses the form of a detective story to investigate who had 'murdered' Aramis, bringing readers to the conclusion that without actors' will or knowledge, their multiple interests gradually transformed and re-transformed the project, until the project became 'something else', a 'beast', as the author calls it:

"Few people think about Aramis -not because it has become so obvious that it no longer counts, but because it has become so inconspicuous that it no longer counts (...) Dispersed among thousands of gestures, myriad reflexes, and immense know-how (...) it survives, but in a state that leaves it unrecognizable" (Latour, 1996: 76).

Explanations about the social mechanisms by which a hybrid partnership transforms into Latour's unrecognizable 'beast' have been relatively scarce. Bryson and colleagues (2009) suggest that actor-network theory can provide a richer understanding of how strategic planning undergoes 
transformations in hybrid partnerships, and how in turn transformations bring about failure or success. An actor-network approach to hybrid partnerships suggests that groups and coalitions emerge spontaneously from chains of recurrent interactions. Actors, both human and non-human, should be treated symmetrically, and their agency studied as a hybrid by-product of 'matters of concern' (i.e., interests). Complementarily to Bryson and colleagues' (2009) indications, Koppenjan and Klijn (2004) and Huxham and Vangen (2013) suggest that decision processes in hybrid partnerships should be increasingly investigated as rich menus from which different actors choose elements that suit their interests at different moments in time, pushing the partnership off track without partners realizing it. We propose that these suggestions can be further advanced by focusing on two core mechanisms theorized in the actor-network approach: translation - i.e. the process by which actors are drawn and converted inside a network such that their interests are "transported with deformation" (Latour, 1987) and inscription - i.e. the result of translating such interests into material forms (Callon, 1999; Latour, 2005). Studying how interests interrelate, take material forms and transform each other in the process also provides a better understanding of partners' efforts to 'produce' truthful facts for each other and for the network at large (see also Bryson et al., 2009). This perspective, we argue, can provide a richer account of how hybrid partnerships transform through time, and when they take unwanted forms or unexpected directions.

\section{Methodology}

\section{The research setting}

We draw on empirical evidence from a field study to explore collaborative practices in a hybrid partnership composed of one university, three industrial associations, a municipality, a chamber of commerce, one private research centre, a public utility company, one regional European Union (EU) office and a regional innovation office located in a highly industrialized 
region of Southwestern Europe. When we entered the field, the stakeholders had recently signed an innovation agreement that contemplated "the need to join resources to obtain mutual benefits related to innovation and knowledge transfer" (cfr.). One year after the initial agreement, partners became operative by planning to build and manage a science park.

The contractual conditions under which the science park was realized implied that the EU Regional Office (REO) used regional funds from the European Development Funding Scheme to co-fund the project, together with the Municipality and the Public Utility Company (PUC), provided the project met a series of essential conditions. First, the park had to be managed by a specialized and certified innovation and technology transfer office -in this case, the Regional Innovation Office (RIO). The role of RIO as stipulated in the financing contracts was that of aggregator, accelerator and promoter of all innovation and technological transfer activities inside the park. Another mandatory condition imposed by the European Union funding scheme concerned the use of the space inside the science park. Accordingly, the University and the private research centre agreed to transfer several labs (research activities, staff and equipment) inside the park, once completed. Upon this agreement, five University research groups and the private research centre received specific funding from EU regional funds to be invested in the research equipment and skilled staff transferred to the park. Additionally, partners committed to allocate $30 \%$ of the available space to dissemination and collaboration activities (conference rooms, co-working etc.). In addition, partners decided that the remaining space would have to be allocated to private companies and/or start-ups. Through an informal agreement, industrial associations took the responsibility to select companies interested in participating in the science park. As they signed the innovation agreement, all partners committed to issue year-by-year funding to RIO's technological transfer activities and each partner designated at least one person to represent their 
interests in RIO's Board of Directors. Additionally, they committed to "freely participate in joint partnership projects" according to "own means and interests" (cfr). The science park (3500 m2) which included also a facility square $(3700 \mathrm{~m} 2)$ was inaugurated two years later as the first science park in a network of regional high-tech science parks co-founded and controlled by REO. It became the prototype for other ten science parks in the network -some of them still under construction. In the appendix, we report a timeframe of the main events in the evolution of the partnership.

\section{Data Sources}

We employed multiple data sources to support our theory building process, specifically, semistructured interviews, archival data, and participant observations.

Semi-structured interviews. From the end of 2013 to the end of 2016 we performed 42 fullyrecorded fully-transcribed semi-structured interviews -averaging 100 minutes each- with directors, politicians, innovation and/or technology transfer managers, researchers and public officers who followed the science park project on behalf of their organizations. We first asked our informants broad questions about what the science park partnership meant for them -i.e. main collaboration goals, how they evaluated them, and whether these changed over time. In the following versions of our research protocol, we asked informants to provide a list of shared projects, activities, and practices related to the science park (i.e. what they expected of the project, how they decided to implement activities, with whom they collaborated, about what, and with what outcomes). Although we did not start our investigation with a specific focus on decisions making and failure mechanisms, after having conducted the first four interviews we realized that, as they reconstructed the evolution of the science park, informants often mentioned problematic issues and emergent strategies to cope with them. Therefore, we included questions to explore these 
themes in subsequent versions of the protocol (i.e. we asked informants about the main difficulties with the project advancement, how they made sense of them and how they decided to go about them). This way, the provisional interpretation emerging from field analysis guided the additional data collection, i.e. theoretical sampling (Strauss \& Corbin, 1998). For example, when we realized that the physical characteristics of the science park (the building, the rooms, etc.) emerged as a recurrent theme, we decided to interview also the architects responsible for the renovation project.

Archival data. During interviews, informants either mentioned or provided us with relevant documents for our research. In parallel, we conducted an autonomous search on publicly available databases. We included 269 official documents and press articles related to the science park and the partnership in the 2009-2016 timespan -documents, websites, protocols, public announcements and calls for funding, brochures, architectural projects, construction site plans.

Participant observation. During 2014, 2015 and 2016 we conducted participant observations of 26 occasions in which the partners met to discuss aspects related to the science park. Among these, 3 shareholder meetings, 10 board of director meetings, 2 events to promote the science park, 2 conferences related to the project and 9 informal meetings between two or more partners. The observations were conducted in most cases by two of the authors that confronted field notes after each event (i.e. event summary, critical incidents, and main topics emerged during observation). Table 1 provides a description of our data sources, including a list of the informants by organization. As highlighted in the context description, responsibilities and leadership were distributed inside the partnership. Given the complexity of participating organizations we chose our informants as to have a good representation of the multiple layers of each organization, the political and top strategy dimensions (i.e. the mayor, local councillors, presidents and chancellors), and the operative dimension, as well (i.e. managing directors, innovation officers, researchers or 
technology transfer managers that were assigned to the project). This allowed us to explore both intra-organizational and interorganizational dynamics related to decision making about the science park across time.

Insert Table 1 about here

\section{Analysis}

We transcribed interviews and observations into field notes and imported them in an integrated database together with collected documents. We collected and analysed our data following the grounded theory approach to build a grounded model (Strauss \& Corbin, 1998). During the first phases of development of the grounded model, we open-coded for recurrent first order concepts, which we then grouped to create second order themes and finally, aggregate theoretical dimensions. Appendix 2 provides a representation of the three levels in our data structure.

As a last step of our coding, we identified relationships between second order themes and aggregate theoretical dimensions. In doing so, we employed a temporal bracketing strategy to turn "a shapeless mass of process data into a series of more discrete but connected blocks" (Langley, 1999:703). This strategy implies a temporal decomposition - i.e. decomposing process data into 'periods' or 'stages', based on a certain continuity within each period and some discontinuities between periods. In our case, we identified distinct stages in the evolution of the partnership which we compared and contrasted with the evolution of the main social processes (risk-opportunity tensions, dysfunctions, strategies to address dysfunctions and inscription of strategies). We represent the relationships between second-order themes and aggregate analytical dimensions in a "substantive" grounded model (Figure 2). To better illustrate our theoretical contribution, we also 
created a more general model (i.e., "formal theory", Glaser and Strauss, 1967) in Figure 3. For the sake of clarity, in Figure 1, 2, and Appendix 2 we use the same colours to identify the four aggregate dimensions (i.e. white, light grey, dark grey and black).

\section{Findings}

To better illustrate our empirical evidence, we anticipate here Figure 1 that presents our substantive grounded model.

Insert Figure 1 about here

\section{Stage 1: Early days}

The initial stage of the project lasted about 18 months and entailed the first attempts to define the main goal and objectives of the partnership. We found that, during this stage, actors interpreted the science park as an opportunity to engage in regional cooperation, on the one hand, and as a risk for competition inside the partnership due to partners' individual agendas, on the other hand. The tension between cooperation opportunity and competition risk made partners undecided about whether to embrace the envisioned opportunity or to take a step back in the face of risk. Partners tried to cope with indecision by mobilizing collaboration promises about specific future collaboration projects and by inscribing the latter in the material space of the science park.

\section{Tension between cooperation (opportunity) and competition (risk)}

In the first years, partners manifested enthusiasm for participating in the realization of a new science park. Yet, since the park was still a plan to be realized, informants talked about their goals using broad and generic terms, such as 'making the most of cooperation' in order to 'gain competitive advantage' or 'creating new synergies' to 'reach new markets and opportunities'. As these terms point out, partners indicated not what the partnership meant for them in the present but 
the advantages it would have generically brought them in the future. The following excerpt from an interview with the President of the Chamber of Commerce shows how collaboration towards an open model of innovation was used by partners as a broad, vague goal that was expected to benefit everybody, from the single partners to the region as a whole:

"I don't know how to explain it, but this project [the new science park] seals a new agreement, at least in my view. In which we say, the world has changed so we must compete not among us, but with the world. It's in the interest of us all, and of our region, that we find a new equilibrium where we can design a new supply chain, a new social welfare system, contribute to the creation of new jobs. So, I don't know if my vision is too idealistic but (...) I believe the science park constitutes an important departing point." (President of Chamber of Commerce)

We found that the broad goal illustrated in the excerpt above - i.e. create a new model of local cooperation for innovation - was understood differently by each partner, and this, in turn, generated fear that individual agendas would have been difficult, or even impossible, to reconcile, and would have shadowed each other. For instance, the Municipality expected that the participation in an innovation partnership could trigger citizens' sympathy, industrialists' willingness to finance public works, and University's contribution to the urban agenda. Therefore, the Municipality top management added to the partnership agenda the strategic goals of their own areas of interest, such as new services for citizens, long-term urban regeneration plans, infrastructure projects, and programs for the promotion of the city brand. In a similar vein, the University saw the science park as a mean to achieve its own strategic goals: improving education (first mission), internationalizing research (second mission), and public engagement (third mission). Similarly, RIO's top management articulated goals such as coordinating technological transfer from University to private firms, providing R\&D and IP consulting for private firms, creating connections with national and European networks for innovation. As each organization specified the cooperation mission of the partnership according to personal interests, the other partners became afraid that other partners' goals would have entered in competition with their 
own. As such, partners expressed fear that individual agendas could have taken over the partnership, and pushed it in uncertain directions:

"We are really hoping to work towards a common goal but you never know because agendas are that different. We have always shown our motivation to work with the public institutions of our territory, take the Municipality and the University, and our support to RIO (...) Obviously we are aware we have different missions, our main concern has been and will always be the performance of our members [i.e. companies] whereas the Municipality is really high on urban development and citizen welfare, the University on research and dissemination (...) I don't think our objectives are conflicting by nature but they may become so if we don't do this [partnership] the right way. So how do we put things together without giving up on our goals? That's the main risk I see right now" (President, Industrial Association 1)

\section{Indecision about science park investments}

The pervasive tension between opportunities for cooperation and competition threats led partners to show hesitation about whether to invest or disinvest in the science park. When in the autumn of 2013 we asked partners specific questions about how the science park would have allowed them to achieve their goals, we received ambiguous answers. Although the project was deemed a 'turning point', it was too early to make accurate planning because risks and opportunities concurred. For instance, although his company had made significant monetary investments in the science park at the beginning of 2013, the innovation manager of PUC was unable to tell us how exactly PUC would have used the science park and remained vague about the next steps to goal implementation:

"It [the science park] has good potential for us, also our President said it on various occasions, but it's not easy to tell what the next steps are, we haven't actually discussed it yet (...). Initially we decided to get involved because it was a great opportunity to collaborate with others in the region, and we also need a new headquarter, so we thought of the science park as a new chapter. But it's not easy to tell. It depends on how we actually build it, and how others will contribute (...) We are committed $100 \%$ but there are so many things to figure out, it would be risky to say we will transfer our offices there or move (name of one of PUC's research centres) there (...)" (Innovation Manager, Public Utility Company)

Like PUC, also informants from RIO, REO, the University and the Industrial Associations explained to us during interviews that the science park was a promising project but still risky and uncertain. The consequence was that, despite the fact partners had formulated their own agendas 
about the science park, they remained relatively inactive for the first year and a half of the partnership, unable to decide whether to further invest and make the most of envisioned cooperation opportunities, or to take a step back and avoid the risks of divergent, opportunistic agendas.

\section{Mobilizing collaboration promises}

To cope with indecision, actors became involved in an intense lobbying campaign to promote their interests and created sub-coalitions to verify the interest of selected partners for specific projects. We thus use the term sub-coalitions to talk about how partners coalesced around collaboration promises. For instance, in the autumn of 2013 and close to the inauguration of the science park, the Municipality communicated repeatedly with citizens in view of the campaign for the political elections. To this purpose, the Mayor presented the science park as 'the citizens' park' (cfr.). During the same period, we retrieved Municipality's interactions with other partners and documented a set of divergent collaboration promises. For instance, during the meetings with the University, Municipality's innovation officers and the Urban Planning Director talked about controlling public access to the building as to protect University's intellectual property rights; During meetings with industrialists, the Mayor underlined the importance of giving the science park an industrial identity, and promised to prioritize private R\&D labs over University labs.

As partners lobbied their interests with selected partners, manifold sub-coalitions were created. For instance, RIO made the same collaboration promises simultaneously to different partners, in the attempt to understand which partners were more willing to finance RIO's projects. In the attempt to create a successful co-working space inside the science park, RIO management promised to allocate the five desks in the co-working space to different industrial associations. In the spring of 2014 , the same desks were being promised to a community of makers associated to 
RIO's fabbing laboratory, to representatives of four professional associations (commercial lawyers, accountants, designers, and architects) and even to us, in support for our research project. We noticed similar trends in separate agreements through which the Chamber of Commerce, the Municipality, the University, PUC and the industrial associations committed themselves to distinct collaboration projects. This evidence testifies that as partners felt threatened by too many broad and self-oriented goals in the partnership, they lobbied other partners for their own goals. Overall, we identified 59 collaboration promises and 22 associated sub-coalitions inside the partnehsip. In table 2 we show the most frequently mentioned, such as an integrated knowledge platform, an education program for children, a dirigible spaceship, a sustainability centre, and even a new University campus.

Insert Table 2 about here

As exemplified in the following excerpt, on the one hand, lobbying allowed partners to manifest willingness to collaborate on specific projects. On the other hand, since promises would have become effective only in the future, partners gained time to assess potential risks related to other partners' agenda. In this sense, collaboration promises were a 'halfway' resolution strategy to indecision: they communicated commitment to the partnership but also left space for partners to exit the commitment in case partnership risks increased. In the following field note, the innovation manager of Industrial Association 1 proposed to Municipality, University and RIO to have weekly discussions about the setup of a knowledge platform in support of the park's activities. While partners intended to show interest and commitment to each other, they also hoped to find out more about what the others were doing, ready to retreat in case envisioned opportunities turned out too costly or unattractive: 
"I think having a knowledge platform would be very useful because, let's face it, many times we duplicate projects with or without knowing, we can't afford that anymore. A detailed database with everyone's past and current projects would be of much help (...) to avoid doing things that are not worth it. If we realize there isn't anything going our direction, it's better to know it in advance and avoid wasting resources. The database is also a hard test for RIO, only time will tell if they will deliver what they promised" (Innovation Manager, Industrial Association 1)

\section{Inscribing collaboration promises}

Reports and press articles written during the first years of the partnership document partners' manifested need to make collaboration promises visible and tangible by associating them with a material artefact. Also during interviews informants repeatedly expressed the need to make collaborations 'feel real'. To reach higher effectiveness, promises had to become visible -i.e. easy to 'see with one's eyes' and 'touch with one's hands'. To this purpose, partners tied each collaboration promise to some specific area of the future science park. The following excerpt exemplifies well the tendency by which partners used the science park as 'a container', as informants termed it, a locus of their manifold goals and expectations about the future. The excerpt is drawn from our first interview with the Municipality's urban planning director who used renderings and simulation videos to describe the project to us:

"Have you seen the renderings? (...) So this is the new access street, you see the huge parking lot in the square? It's where the researchers, and the entrepreneurs, and the other people will park, and here is where they get in and will find a filter at the reception sending them to the right person (...) because we believe that the space must become more and more integrated, without separations, so we are trying to create easy access so that we can all feel part of the same community" (Municipality Urban Planning Director)

The park was intended as a 'home' for partners' strategic collaboration promises. It served to make their interests more visible to each other, and thus, more alive:

"So, the park has the function to represent us all, to confirm to the world that we exist as an entity, and gives a physical representation of what we do" (University Vice-Chancellor)"

Interestingly, as the following excerpt suggests, inscriptions allowed partners both to seek out opportunities (i.e. making visible specific projects that they were interested in), and avoid risks related to other partners' agendas (pushing others make their own interests visible): 
"Science parks have not been completed yet, but the idea is to use this intermediate phase to make the most of the opportunity, like create also a database where we can stock and trace relevant contacts and...build a platform trough which we can actually stimulate innovation activities in our region, meaning not just (that) a company comes to a science park asking for a specific project, but that we, partners, take immediate action, like events to attract industry attention, promotion of large scale cross-disciplinary projects, expert roundtables and so on (...) In our experience, this can avoid what science park stakeholders usually lament: investing time and resources that don't pay off" (REO Innovation Manager 1)

\section{Stage 2: Development}

As soon as the science park started to materialize, the collaboration promises that partners had inscribed in the future space triggered a new set of unexpected tensions between an overflow of collaboration opportunities and the risk of not being able to implement all of them given the limited space of the science park. The difference with respect to the early stage is that envisioned opportunities were no longer associated to broad goals but to specific collaboration promises. In addition, partners' perceptions of risks switched from the awareness that disjointed agendas were difficult to bind together, to the fear that efforts to implement such different agendas inside a given space would have steered conflict inside the partnership. Within the new opportunity-risk tension, partners continued to show hesitations similar to the ones in the previous phases (i.e., indecision). Additionally, since partners tried to avoid choosing between collaboration promises, they engaged in procrastination. After two years of being stuck in indecision and procrastination, partners enacted a coping strategy which consisted in rolling collaboration promises in an extended physical space that they called 'innovation multiplex'. As in the previous phase, renewed collaboration promises were brought to life by inscribing them in the prospected buildings of the multiplex.

\section{Tension between collaboration (opportunity) and conflict (risk)}

The park was completed at the end of 2013. Both the external construction and the internal space have been described in the press as 'futuristic', 'innovative', and 'attractive'. Nevertheless, the envisioned opportunity to implement specific collaboration projects 
coupled with the perceived risk of conflict about their implementation to generate a tension that partners lamented over the two years following the inauguration of the park.

With respect to the previous stage, goals became more articulated but also more numerous and dispersive. On the one hand, partners praised the conspicuous number of collaboration promises as a sign of the partnership's vitality. On the other hand, they complained that the space available was too small to allow all collaboration promises to materialize. To give an example, the head of a University research lab explained that the assigned space was 'insufficient' to transfer the group's entire staff and equipment, and that moving into the science park appeared cost-inefficient. Similar claims were made by industrial associations to explain why they did not occupy their co-working desks in the park. The RIO managing director himself complained that the science park was too small to host all partners and noted that the lack of space stopped RIO from accomplishing its brokering role:

"They expect us to play Lords of the Rings in Silicon Valley but we have a $175 \mathrm{~m} 2$ office in a $3000 \mathrm{~m} 2$ building. What kind of Silicon Valley is that and what kind of Kings are we? This is not what we expected. If I have to make the place work, I need more space (...). Everybody is telling me the same thing, there is not enough space, so nobody wants to come here after all. One year has passed and the University hasn't transferred at least one lab, can you imagine that?" (RIO Managing Director)

A consequence of the tension between collaboration opportunity and risk of conflict was that the co-working space remained unutilized. Interestingly, given that collaboration promises were open-ended and involved only few partners at a time, insufficient space was noticed only after the science park materialized. When asked if they had foreseen the space's insufficiency with respect to collaboration promises, most informants explained that lobbying was a necessary activity to get a complex project going, but how much of the lobbying would have turned into actual projects, was difficult to foresee. The following 
excerpt of a BoD meeting gives an example of how collaboration promises shadowed the evaluation of available space, and nurtured the need for additional space:

RIO President: "Last week we signed an agreement with Municipality for the fabbing lab, and in the same day we also received two manifestations of interests that you can find on your desks, one to host a new University start up and one for an R\&D lab that would like to transfer in the science park (...) The potential is huge, we have all the players and all the necessary conditions, but the important thing is we don't end up seeing this as a formal black-box where we come, listen, and then leave. So people need ownership, they need to feel at the centre of this (...)

RIO Managing Director: What the President is trying to tell you in an elegant way is that I cannot tell these people there is no room for them, and no resources. Financially and institutionally speaking, RIO cannot afford to say no to opportunities, especially from these people"

The extract above also underlines that partners refuse to choose which collaboration promises to implement because they are averse to choosing which ones not to implement. The top management of RIO argues that, politically speaking, selecting collaboration promises can weaken the partnership. Not only can it increase the level of conflict, but it can demotivate partners to 'assume ownership'.

\section{Indecision and procrastination}

During the two years consecutive to the inauguration of the park, we asked our informants and consulted internal reports and budget plans and found that none of the identified collaboration promises had turned into an operative project nor was mentioned in organizations' official documents or included in budget forecasts. We then checked whether collaboration promises had been negotiated by partners over time, and whether their number had decreased because of negotiation. To our surprise, we acknowledged a considerable lack of negotiation practices and an increase of collaboration promises as the partnership evolved. This tendency was signalled by the presence of two decision process dysfunctions: a tendency towards indecision and a tendency towards procrastination.

Just as in stage 1, partners hesitated to allocate new resources to the partnership, invoking both opportunities and risks. For instance, while informants confirmed their intention to invest in 
specific collaboration promises, they also lamented that implementing them from scratch was risky and complicated because they still had a limited understanding of what they could accomplish together. On top of this, we found evidence of procrastination. Given that the available space was limited, there was no set priority about which collaboration projects should have gone first, and partners did not want to generate conflicts with other partners, the implementation of collaboration promises was constantly postponed. The following excerpt from our third interview with RIO's managing director exemplifies the cumulative effect of indecision and procrastination, as follows:

"We don't need to underestimate this aspect (...) people from (name of Industrial Associations 1, 2 and 3) ask themselves: Why should I collaborate with RIO? Why should I send a person to work in the science park? Why should I move my staff and lab facilities there? What are the advantages and costs I will need to sustain? We can't pretend to answer right away, we will need time to trust each other and to convince each other [that] doubts are no longer necessary" (RIO Managing Director)

As the excerpt suggests, the accumulation of indecision and procrastination is generated by a lack of certainty about the trajectory of the partnership, the benefits that each partnering organization will obtain in the future, and the unpredictable agendas of the other partners.

\section{Rolling collaboration promises}

To deal with the state of inertia generated by indecisions and procrastinations, partners tried to revive the science park project thanks to a strategy that we labelled 'rolling collaboration promises'. The characterizing aspect of the strategy is that instead of admitting the difficulties of the project and taking concrete actions to overcome them, partners preferred to roll out collaboration promises further away into the future and projected them onto a new extended space. Specifically, partners explained that upon realizing that many collaboration promises had not materialized, they decided to lobby with the other partners for an extended park called the innovation multiplex. The multiplex had the advantage of being large enough to host all preexisting collaboration promises, and even encourage new ones: 
"Our ambition is also our biggest difficulty. [...] the first difficulty is doing things together, meeting to decide and plan things together. Now we have a project for the future, but we don't have the physical place that can host all that, at least not yet, so this is why the innovation multiplex (...) We hope our members will have more advantages. As a matter of fact, we proposed to (name of president of Municipality-PUC joint venture) that at least half of the spaces in building \#18 are rented to private firms with cutting-edge R\&D labs, such as (names of two private firms)" (Innovation Manager, Industrial Association 1)

\section{Inscribing renewed collaboration promises}

Document analysis suggests that after the inauguration of the science park, partners' attention shifted completely from the empty science park to restructuring the remaining buildings of the innovation multiplex. This mechanism was coherent with the strategy of keeping collaboration promises alive by rolling them into the future and inscribing them in a larger physical space. To facilitate the process of material inscription, the urban planning director of the Municipality created a physical model of the future innovation multiplex dividing areas into sub-areas, buildings, and external infrastructures. As partners renewed their collaboration promises, they sometimes referred to this physical model. The following excerpt from a local press article further exemplifies the mechanism by which renewed collaboration promises such as creating a University campus or managing a co-working area, were attached to specific building in the future multiplex:

"After the success of the science park, the Municipality has decided to expand the purpose scale. After building \#17, now it's turn for building \#18 to be turned into an innovation multiplex, a house for the most innovative high-tech business of the area [...] Now, close to the science park, a Mechatronic Park will rise, and around it, a series of innovative professional services in support of nascent technologies [...] "Interest from the companies has been noteworthy argues (name of Municipality Urban Planning Director) (...) in order to meet their requests, we also included the restructuration of building \# 15 on our priority list".

\section{Stage 3: Extension}

Although partners hoped to solve dysfunctions related to opportunity-risks tensions by inscribing rolling collaboration promises in an extended space, paradoxically, a new tension between opportunity (i.e. greater visibility) and risk (i.e. blame for partnership failure) emerged. 
Not only did the new tension perpetuate indecision and procrastination, but it also generated escalation of commitment.

\section{Tension between visibility (opportunity) and blame (risk)}

As time passed, informants referred to the future innovation multiplex as both a valuable occasion for greater visibility, and as a risky initiative that might have triggered public blame. Since it was first announced (i.e. promised), the innovation multiplex had received extensive press coverage as "the second largest innovation project in the region" and "one of the most complex and inter-disciplinary collaborations on a national and international scale”. Partners often referred to the renewed public attention as an opportunity to become more visible and impactful in their community, or to "play bigger", as the mayor and the president of Industrial Association 1 termed it. Interestingly, the new opportunity revived partners' need for collaboration and stimulated additional collaboration promises. For instance, as the expansion project was designed, new sub-coalitions were also set up: The Municipality and the Private Research Centre made preliminary agreements to create an international centre for agricultural research, the Municipality and the University promised to initiate a collaboration for an Education Valley, while the Municipality and PUC discussed the opportunities for a new sustainability research centre. Also, a larger sub-coalition was created to modify the governance of RIO. The collective purpose was to turn RIO into a collaboration platform for the innovation multiplex (see table 3 ). On the other hand, however, partners expressed their concern that embarking on a big-scale project might increase the risk of receiving public blame. Specifically, during BoD meetings, partners compared the multiplex project with the existing science park which they saw as a failed experiment: One year after the opening ceremony, only a small part of the actors had actually transferred to the science park and even at two years' distance most spaces were still vacant. In addition, even the 
few labs which had moved inside the park at the beginning of 2015 inhabited closed spaces and were often locked by key. The co-working spaces were not frequented, and the conference rooms were only sporadically in use. This gave visitors who walked in the corridors the impression that the park was not inhabited at all. During interviews and BoD meetings, partners manifested the fear of being publicly blamed in case the innovation multiplex turned out the same way, that is, 'only as a real estate investment. An urban requalification project [..., but] empty' and 'worthless from an open innovation standpoint” (Managing Director Industrial Association 2).

\section{Indecision, procrastination, and escalation of commitment}

Two years after the inauguration, only five researchers had transferred to the science park, and most spaces which had been destined to research labs remained empty. Yet, despite indecision and procrastination, goals and promises continued to proliferate well beyond the levels of the early phases because partners started allocating new resources to the expansion project. It is interesting to notice that all partners continued to make generic investments for the renovation of the innovation multiplex (i.e. infrastructure investments) which had five times the budget of the initial science park. To give some examples, the Municipality financed a Joint Venture with PUC to manage the design, consolidation and renovation of the new buildings; RIO and the Private Research Lab purchased new office space in the buildings under renovation; the industrial associations lobbied the project expansion and acted as an intermediator for the acquisition of space by private firms. However, partners continued to postpone specific investments in collaboration promises. It often happened that partners transitioned from indecision about whether to invest or disinvest to the hope that postponing events would have brought by itself solutions, concluding that minimum investments had to be made to 'buy time' and keep the project alive. The following excerpt from an interview with the area manager of Industrial Association 1 shows 
how partners' perception of 'no turning back' kept together indecision and procrastination, and pushed for a time-buying escalation of commitment:

"I know some might say we are not technically there and we are not working together as a real organization, but everybody is so positive about it, we know it will come, we just have to keep on being patient. You don't manage to create everything from scratch; networks take time, developing an open mentality may take even longer (...) but at least we did it. We created this bond and now we are tied together with an umbilical cord. Now the first results are on their way. As we restructure the other buildings, we will start bringing in the companies, and my dream is to build a space where we can have a pair of big companies to act as project engines, and the R\&D offices of some smaller companies, ideally their suppliers, and also connections with some existing or potential clients in related sectors. (...). I have already talked to the Chamber of Commerce about it and they promised their support. So, we continue to believe in this project. I know everyone else is doing the same". (Innovation Officer 2 Industrial Association 1).

As suggested by the previous excerpt, the perception of no turning back was associated with the existence of a physical space which contained not just collaboration promises but also partners' reputations. While newspapers praised visible features of the multiplex such as the innovative design and strategic position, partners feared that the same visibility could have turned against them. For instance, the director of the private research lab termed the new project as "an empty box with a big red ribbon on top" and RIO's general manager as the "locus of too many dreams that would have probably never come true”.

It is also noteworthy that the partnership is still ongoing, the innovation multiplex is still in the renovation phase, and our vicious circle is still in the making. Although we did not find evidence of a new, well-defined strategy to deal with indecision, procrastination and escalation, we collected data about partners' manifested urge to find new ways to "exit the blackhole in which we say one thing and change our mind the day after", and stop "throw [ing] money down the gutter to renovate buildings without destination”, as our informants explained. Only time will tell whether a new round of collaboration promises, or a different strategy, will be formulated to deal with an increasingly dissatisfying situation.

\section{Context conditions and vicious circles of decision}


While we collected and analysed data, we were surprised that dysfunctions accumulated over time despite partners' attempts to resolve them. In addition to the categories in our grounded model, we identified a set of context characteristics related to the hybrid partnership - dispersed responsibility and partnership long-term horizon- that further explain the vicious circle of decision here portrayed.

\section{Dispersed responsibility}

One of the main characteristics of a hybrid partnership is that involved parties mobilize heterogeneous interests which must be negotiated and aligned. The loose contractual conditions of the partnership (see methodology section) implied that "the science park belonged to everybody, but nobody really owned it" (RIO President). As we have shown, by signing the innovation agreement, partners committed to allocate time and resources to the science park, but they could discretionally choose the extent and type of involvement. Given the loose contractual conditions, the park was perceived by stakeholders as a collective melting pot to which everyone contributed but for which no one assumed direct responsibility. For instance, after the design and execution stages came to an end, PUC and the Municipality considered their mission completed and delegated the operative life of the park to RIO. Additionally, the Chamber of Commerce did not have a clear understanding of its operative role once the science park became active and thus avoided assigning staff members to purposes that were not entirely clear. We did find that partners had different roles inside the partnership (i.e. Municipality led the funding and construction phases, the Chamber of Commerce acted as funder, RIO as broker) (see also Geddes, 2008). However, to our surprise, these roles were not used to give a direction to the partnership.

\section{Long-term horizon}


Since the time horizon of the partnership was indefinite, partners took all the necessary time to make and unmake collaboration promises, indulge in indecision, procrastinate, and perform scale expansions. This is consistent with evidence that broad horizons facilitate indecision (Denis et al., 2011), and stimulate partners to make projects bigger and more expensive (Staw et al., 1993). While lack of deadlines and open budgets can foster partners' flexibility, autonomy and initiative (Selsky \& Parker, 2005; Crosby et al., 2006), they can also set partners adrift from their initial intentions.

\section{Discussion}

Our field study investigated longitudinally a hybrid partnership aimed at setting up a new science park. Figure 2 gives a 'formal', i.e. more theoretical (Glaser and Strauss, 1967), representation of the components of our substantive grounded model (Figure 2). Summarizing, we have shown that the mechanism by which dysfunctions accumulate to create vicious circles of decision entails four interrelated aspects: 1) opportunity-risks tensions that generate 2) dysfunctions in decision making that in turn trigger 3) strategies intended to solve states of indecision, procrastination, and escalation, enacted with the hope of reaching a new state in which opportunity-risk tensions are overcome. However, as the strategies become 4) inscribed in a material space, new opportunity-risks tensions arise under the form of unintended consequences, generating new dysfunctions, and new strategies of resolution, new rounds of inscription and so on. A set of context characteristics - long-term horizon and dispersed responsibility - allowed for further grounding of our findings. As follows, we discuss the elements of our formal model at the light of the literature to which it contributes. We first discuss how the model answers our research question about the accumulation of dysfunctions in the evolution of hybrid partnerships. Then, we 
discuss other two emergent contributions: risk-opportunity framing and the role of sociomateriality in complex multi-party collaborations.

Insert Figure 2 about here

\section{Vicious circles of decision in hybrid partnerships}

As a primary contribution, we advance existing understanding of how dysfunctional decisions accumulate inside a partnership, and why. While studies so far have focused on the role of single dysfunctions, we explain how multiple dysfunctions accumulate and interact to create vicious circles of decision. We thus propose a change of perspective, from decision dysfunctions to vicious circles of decision. Although existing evidence suggests partnership trajectories are non-linear (Austin \& Seitanidi, 2012b; Le Ber \& Branzei, 2010; Westley \& Vredenburg, 1997), they rarely explain the factors that lead to unexpected shifts of directions. With respect to previous studies, our findings bring several elements of novelty. First, we suggest that partners' constant oscillation between opportunity-seeking and risk-avoiding behaviours is fuelled by the context conditions that characterize a hybrid partnership and can influence its entire lifecycle. Specifically, setting up a partnership with long-term horizons in which partners mobilize broad and heterogeneous goals (Hardy \& Phillips, 1998; Selsky \& Parker, 2005; Waddock, 1989) exposes partners to much more stimuli in terms of opportunities and risks than they can initially manage, and triggers indecision about whether to step back or push forward. Although we cannot infer that decision dysfunctions always follow the same order, nor that one type of dysfunction is more determinant than others, we argue that in complex partnerships in which partners perceive that opportunities and risks are both significant and concurrent, indecision plays a key role in triggering accumulation. 
We theorize that the constant oscillation between risks and opportunities creates vicious circles of decision when it gives rise to what we called 'halfway solutions': strategies by which partners try to advance a collaboration while also preparing to move backwards at any time. Halfway solutions are not partial or compromising solutions because they do not indicate progression towards a desired state of fact, nor do they imply integration and synthesis. In the same way, they are not synonyms to remaining stuck 'betwixt and between' because they imply constant disordered movement. Instead, we argue that solutions remain halfway when they imply constant oscillations between two bounded conditions (i.e., opportunity and risk) that cannot be overcome. Specifically, as partners try to fight against complexity (i.e. overflow of envisioned opportunities and risks), their solutions are constrained and distorted by the very complexity they are trying to escape. Most studies have claimed that dysfunctions deriving from opportunity-risk tensions can and must be solved by enacting opposite coping strategies (e.g. indecision can be fought through commitment, escalation of commitment can be fought by slowing down and weighting pros and cons, etc.). Conversely, by halfway solutions we refer to cases in which coping strategies that do not solve opportunity-risk tensions merely swing the pendulum from one side to the other.

Importantly, the study of more than one dysfunction at a time shows that intended ways to solve a dysfunction trigger unintended complications and pave the road for new dysfunctions. For instance, the dialectical relationship between indecision and choice averseness sets the ground for procrastination. If individuals perceive the act of choosing as unappealing or destructive (Raisin, 2006), the availability of many similar alternatives (e.g. collaboration promises) not only deepens the state of indecision, but can also lead to procrastination. We thus take distance from Denis et al.'s (2011) study in that we see indecision not only as self-perpetuating dysfunction but also as trigger for other more complex dysfunctions. 
Just as indecision is a precursor of procrastination, we also highlight that procrastination can be a precursor of escalation. In line with more recent works, we argue that escalation of commitment should be studied as a multiform, non-linear process which can entail also stances of postponement and ambiguity (see also McNamara et al., 2002; Pan et al., 2006). When collaboration goals are too generic, partners try to fuel the partnership with the promise of specific (i.e. materially tangible) courses of action, but as these turn out difficult or even impossible to achieve, they once more withdraw in a more generic dimension which allows to buy additional time. We thus suggest that halfway solutions can be explained as the result of choice averseness and as compulsive alternations between broad goals and highly specific courses of action.

Last, we contribute to understanding how halfway solutions make things worse by trying to make them better. Our work confirms that courses of actions which are strongly constrained by risk-opportunity tensions remain strategically ambiguous (see also Abdallah \& Langley, 2014; Denis et al, 2011). However, instead of seeing strategic ambiguity as a fluid and flexible resource for partners (Le Ber \& Branzei, 2010), we describe the rigidity that derives from inscribing strategic ambiguity in material artefacts. By association to a physical entity, halfway solutions (in our case, collaboration promises) become "black-boxed" (Callon, 1999) or "frozen" (Bowker \& Star, 1994). While the intended consequence of inscription is to make halfway solutions more stable, these also become more rigid and irreversible, bringing about the unintended consequence of renewed risk-opportunity tensions. Specifically, since inscriptions are potentially visible to everyone, partners can no longer cancel them, but only 'conceal' them by means of other strategies such as procrastination, or escalation. For instance, our model displays that even if partners failed to maintain collaboration promises, they behaved as if each promise was already effective and thus irreducible: taking out one piece risked tearing down the whole construction. As disordered pieces 
of commitment accumulated, partners risked crawling under their weight and tried new strategies to lighten their burden. In synthesis, inscription generates more of what it tries to solve (i.e. new tensions and new halfway solutions) because it takes flexibility out of halfway solutions.

\section{Advancing the organizational literature on opportunity-risk framing and decisions}

Our findings also bring a contribution to the organizational literature on opportunity-risk framing. Differently from previous studies that have emphasized either the negative consequences of unbalanced risk-opportunity frames, or the positive role of cultivating dialectic balance between the two (for a review see Cornelissen \& Werner, 2014), we draw attention to those mechanisms by which paradoxical tensions between opportunity and risk create vicious circles of decision in collaboration settings. Specifically, the prospect theory approach (Tversky \& Kahneman, 1981) and the rigidity-threat model (see Dutton \& Jackson, 1987; Sitkin \& Pablo, 1992; George et al., 2006) have assumed that organizational actors are able to make either risks or opportunities prevail. Too much focus on risks can be solved by increasing attention to opportunities, and vice versa. Paradox studies, on the contrary, have mainly looked at situations in which perceptions of risks and opportunities concur to the creation of paradoxical tensions, suggesting the importance of maintaining a dynamic equilibrium between risks and opportunities. By dynamic equilibrium authors refer to how organizations can attend to competing demands simultaneously, accepting that tensions can be silenced only temporarily and that cyclical responses will always be necessary (Smith \& Lewis, 2011). Interestingly, some rare studies of cross-sector partnerships (Clegg et al., 2002; Le Ber \& Branzei, 2010; Marrewijk et al. 2008) and inter-organizational alliances (Das \& Teng, 2000) have also adopted the paradox perspective. For instance, Das and Teng (2000) have suggested that inter-organizational alliances fail because they are unable to maintain a balance between opposite tensions such as belonging and non-belonging, competition and collaboration, 
or empowerment and control. Similarly, in hybrid partnerships, Clegg and colleagues (2002) and Koppenjan and Enserink (2009) have suggested that getting out of balance erodes motivation to collaboration (too much risk condition) and triggers complacency (too many opportunities condition). While paradox studies see risk-opportunity tension as progressive and generative, we theorize that it may lead a collaboration adrift towards vicious circles of decision. Even if we did not measure the extent to which our informants operated with balanced perceptions of risks and opportunities, we observed their swinging from one side of the pendulum to the other, unable to make up their minds about whether the partnership entailed more risks or opportunities. The difference between our findings and the claims of paradox studies, we argue, lies in the attention to halfway solutions, material inscriptions and unintended consequences (i.e. renewed tensions).

\section{A temporal view of material inscriptions for collaboration}

Our model brings an unexpected contribution about the role of material inscription in pluralistic collaboration settings such as hybrid partnerships. Our findings are consistent with an actor-network approach that views the evolution of hybrid partnerships as an emergent process initiated and guided by partners' specific interests (see also Crosby et al., 2009; Denis et al., 2011). Through processes of translation and inscription, partners try to drag other actors into the collaborative effort but end up conditioned by these very attempts (Latour, 1987; 2005). We have shown that material inscription is central in this process. In the initial stages of a complex project, members of hybrid partnerships may perceive materiality as a flexible resource. For collaboration promises to be real, that is, taken seriously by everyone, they had to become visible, that is, inscribed in a material space, even though that space had yet to be realized. This way, the science park not only provided square footage for research and innovation projects, but due to partners' compelling needs to convert abstractions into something more palpable, stable, and enduring, it 
became an iconography of the future (De Vaujany \& Vaast, 2016). Since spaces and objects are always partial in the beginning (De Vaujany \& Mitev, 2013; Introna, 2013), they become containers for multiple and often contrasting interpretations, taking upon the contradictory wishes and decisions of their users and creators (De Vaujany \& Vaast, 2014; Orlikowski, 1992). A collaboration object that still needs to be realized (i.e. design stage) or is incomplete (i.e. realization stage) may thus fuel an overflow of interpretation and agency in the partnership. Such overflow may 'turn against' those who have generated it, leaving a project unrecognizable, as was the case for Latour's (1996) Aramis project.

Importantly, our findings show that, paradoxically, the path to unrecognition passes through actors' attempts to make their intentions recognizable (i.e. visible) to each other. We have shown that partners' dance between highly generic and highly specific courses of action is guided by their constant search for material visibility. The desire for public visibility, on the one hand, and the fear of negative visibility, on the other, push actors to inscribe ambiguous promises into material forms. This strategy allows to seize visibility opportunities while also gaining the (illusion) of higher controllability. However, such strategy turned out highly unprofitable because of the unintended consequences it entailed. De Vaujany and Vaast (2014) have proposed that an organization's claims to legitimacy and the spaces it occupies are imbricated, such that one transforms the other in a tempo that neither can control. Following the actor-network perspective, we document the unpredictability of such imbrications (see also the seminal studies of Callon, 1999 and Latour, 1987). When material inscriptions go in overflow with respect to an artefact's material capacity, partners may become scared of the very overflow that they generated, withdraw from intended courses of action, and enact alternative strategies that can seem irrational to an external eye but for partners represent the only way out. It is important to notice that inscriptions have an immanent 
nature: they are easier to conceal or to expand than they are to dismantle. From such perspective, inscriptions become a socio-material legacy based on long-term accumulation of legitimation attempts and actors' myriad actions and reactions to these attempts (De Vaujany \& Vaast, 2014; Mahring et al., 2004). Significantly, while so far studies have focused on retrospective (i.e. historical) legacy, we argue that spaces may display a socio-material legacy even before being built (i.e. prospective legacy).

\section{Implications for practice}

We highlight that managerial strategies to reduce vicious mechanisms inside hybrid partnerships should be considered very carefully because attempts to escape one type of decision problem may create the seeds for another decision problem. Accordingly, advices such as "Begin with doubts!", "Be vigilant!”, “Set limits and don’t go beyond them!” (Drummond, 2017; Staw \& Ross, 1993) may push partners towards indecision and procrastination. In the same way, doing something just for the sake of exiting indecision (Denis et al., 2011) or making goals more proximate to avoid procrastination (Harris \& Sutton, 1983; Steel, 2007) may cause escalation of commitment.

Practitioners should also pay attention to their compelling need to 'secure' ambiguous promises by tying them to material artefacts. While material inscriptions can bring certainty on the short term, they can also become unsustainable on the long run. We suggest that partnership artefacts must be kept flexible, and updated as the relationship between partners evolves. Working with prototypes may allow partners to clarify ambiguous inscriptions in early stages without fearing irremediable consequences such as partnership breakdown. It is necessary that all participants take part in prototyping (Hagel \& Brown, 2005), and that a functional leadership structure gradually emerges around the artefacts (Klijn, 2008). Prototypes can be made more 
reliable if used by multiple actors (managers, brokers, partners. etc.) to cross-check for goal alignment and coordination.

Last, while paradox studies advise to accept and live with opportunity-risk tensions (Clegg et al., 2002; Das \& Teng, 2002), we also draw attention to situations in which partners may use this suggestion as an excuse to escape unpleasant negotiations. A large governance system based on constant consultation may provide a valuable solution to inertia problems.

\section{Limitations and concluding remarks}

While we believe our study offers several theoretical insights, it is not without limitations. First, we deal with a longitudinal case study with limited generalizability and the described processes are anchored in the specific context and interrelations that we observed. We also recognize that not all partners have the same level of interest and the same role inside a partnership. Indeed, our data suggest that some actors (i.e. Municipality, RIO) occupied more central roles with respect to others. Future research could investigate whether different governance systems influence vicious circles of decision (Geddes, 2008). We also do not imply that dysfunctions always accumulate in the same way. Future research may look at vicious circles of decision in other forms of hybrid partnership (Selsky \& Parker, 2005). Also, we acknowledge that materiality may play a less important role in partnerships with less tangible projects, and suggest further crosscase analyses of the inscription process.

All in all, hybrid partnerships are increasingly common and are expected to bring major benefits for individuals, organizations, and the society at large. In this study, we focused on the grey areas of hybrid partnership projects, drawing attention to vicious circles of decisions across a project's lifecycle and describing why hybrid projects that lose their way are so difficult to put back on track. 


\section{References}

Abdallah, C., \& Langley, A. 2014. The double edge of ambiguity in strategic planning. Journal of Management Studies, 51(2): 235-264.

Akerlof, G. A. 1991. Procrastination and obedience. The American Economic Review, 81(2): 119.

Arkes, H. R., \& Blumer, C. 1985. The psychology of sunk cost. Organizational Behavior and Human Decision Processes, 35(1): 124-140.

Austin, J. E., \& Seitanidi, M. M. 2012a. Collaborative value creation: A review of partnering between nonprofits and businesses: Part I. Value creation spectrum and collaboration stages. Nonprofit and Voluntary Sector Quarterly: 0899764012450777.

Austin, J. E., \& Seitanidi, M. M. 2012b. Collaborative value creation: A review of partnering between nonprofits and businesses. Part 2: Partnership processes and outcomes. Nonprofit and Voluntary Sector Quarterly

Bowker, G., \& Star, S. L. 1994. Knowledge and infrastructure in international information management: Problems of classification and coding. Information acumen: The understanding and use of knowledge in modern business: 187-216.

Brockner, J. 1992. The escalation of commitment to a failing course of action: Toward theoretical progress. Academy of Management Review, 17(1): 39-61.

Brockner, J., \& Rubin, J. Z. 1985. Entrapment in escalating conflicts. Social Psychological Analysis (New York: Springer, 1985).

Bryson, J. M., Crosby, B. C., \& Stone, M. M. 2006. The design and implementation of crosssector collaborations: Propositions from the literature. Public Administration Review: 44-55.

Callon, M. 1999. Actor-network theory—the market test. The Sociological Review, 47(1_suppl): 181-195.

Clegg, S. R., da Cunha, J. V., \& e Cunha, M. P. 2002. Management paradoxes: A relational view. Human Relations, 55(5): 483-503.

Cornelissen, J. P., \& Werner, M. D. 2014. Putting framing in perspective: A review of framing and frame analysis across the management and organizational literature. Academy of Management Annals, 8(1): 181-235.

Das, T. K., \& Teng, B.-S. 2000. Instabilities of strategic alliances: An internal tensions perspective. Organization Science, 11(1): 77-101.

De Vaujany, F.-X., \& Vaast, E. 2013. If these walls could talk: the mutual construction of organizational space and legitimacy. Organization Science, 25(3): 713-731.

De Vaujany, F.-X., \& Vaast, E. 2016. Matters of visuality in legitimation practices: Dual iconographies in a meeting room. Organization, 23(5): 763-790.

Denis, J.-L., Dompierre, G., Langley, A., \& Rouleau, L. 2011. Escalating indecision: Between reification and strategic ambiguity. Organization Science, 22(1): 225-244.

Drummond, H. 2017. Megaproject escalation of commitment. An update and appraisal, Vol. Flyvbjerg, B. (Ed.). (2017). The Oxford Handbook of Megaproject Management. 
Dutton, J. E., \& Jackson, S. E. 1987. Categorizing strategic issues: Links to organizational action. Academy of Management Review, 12(1): 76-90.

Flyvbjerg, B., Skamris Holm, M. K., \& Buhl, S. L. 2005. How (in) accurate are demand forecasts in public works projects? The case of transportation. Journal of the American Planning Association, 71(2): 131-146.

Geddes, M. 2008. Inter-organizational Relationships in Local and Regional Development Partnerships, The Oxford handbook of inter-organizational relations.

George, E., Chattopadhyay, P., Sitkin, S. B., \& Barden, J. 2006. Cognitive underpinnings of institutional persistence and change: A framing perspective. Academy of Management Review, 31(2): 347-365.

Googins, B. K., \& Rochlin, S. A. 2000. Creating the partnership society: Understanding the rhetoric and reality of cross-sectoral partnerships. Business and Society Review, 105(1): 127144.

Gray, B. 1989. Collaborating: finding common ground for multiparty solutions: San Francisco: Jossey

Hagel 3rd, J., \& Brown, J. S. 2005. Productive friction: how difficult business partnerships can accelerate innovation. Harvard Business Review, 83(2): 82-91, 148.

Hardy, C., \& Phillips, N. 1998. Strategies of engagement: Lessons from the critical examination of collaboration and conflict in an interorganizational domain. Organization Science, 9(2): 217-230.

Harris, N. N., \& Sutton, R. I. 1983. Task procrastination in organizations: A framework for research. Human Relations, 36(11): 987-995.

Hodge, G. A., \& Greve, C. 2007. Public-private partnerships: an international performance review. Public Administration Review, 67(3): 545-558.

Hodgkinson, G. P., \& Wright, G. 2002. Confronting strategic inertia in a top management team: Learning from failure. Organization Studies, 23(6): 949-977.

Huxham, C. 1996. Advantage or inertia? Making collaboration work. The new management reader: $238-254$.

Huxham, C., \& Vangen, S. 2000a. Leadership in the shaping and implementation of collaboration agendas: How things happen in a (not quite) joined-up world. Academy of Management Journal, 43(6): 1159-1175.

Huxham, C., \& Vangen, S. 2000b. Ambiguity, complexity and dynamics in the membership of collaboration. Human Relations, 53(6): 771-806.

Huxham, C., \& Vangen, S. 2013. Managing to collaborate: The theory and practice of collaborative advantage: Routledge.

Introna, L. D. 2013. Epilogue: Performativity and the becoming of sociomaterial assemblages, Materiality and space: 330-342: Springer.

Klijn, E.-H. 2008. Policy and implementation networks: Managing complex interactions. The Oxford handbook of inter-organizational relations: 118-146. 
Koppenjan, J. F., \& Enserink, B. 2009. Public-private partnerships in urban infrastructures: reconciling private sector participation and sustainability. Public Administration Review, 69(2): 284-296.

Koppenjan, J. F. M., \& Klijn, E.-H. 2004. Managing uncertainties in networks: a network approach to problem solving and decision making: Psychology Press.

Langley, A. 1999. Strategies for theorizing from process data. Academy of Management Review, 24(4): 691-710.

Latour, B. 1987. Science in action: How to follow scientists and engineers through society: Harvard University Press.

Latour, B. 1996. Aramis, or, The love of technology: Harvard University Press Cambridge, MA.

Latour, B. 2005. Reassembling the social: An introduction to actor-network-theory: Oxford university press.

Le Ber, M. J., \& Branzei, O. 2010. (Re) forming strategic cross-sector partnerships relational processes of social innovation. Business \& Society, 49(1): 140-172.

Linder, S. H., \& Rosenau, P. V. 2000. Mapping the terrain of public-private policy partnership: Public-Private Policy Partnerships. Cambridge, Mass., MIT Press.

Mähring, M., Holmström, J., Keil, M., \& Montealegre, R. 2004. Trojan actor-networks and swift translation: Bringing actor-network theory to IT project escalation studies. Information Technology \& People, 17(2): 210-238.

McNamara, G., Moon, H., \& Bromiley, P. 2002. Banking on commitment: Intended and unintended consequences of an organization's attempt to attenuate escalation of commitment. Academy of Management Journal, 45(2): 443-452.

Orlikowski, W. J. (1992). The duality of technology: Rethinking the concept of technology in organizations. Organization Science, 3(3), 398-427.

Pan, G., Pan, S. L., Newman, M., \& Flynn, D. 2006. Escalation and de-escalation of commitment: a commitment transformation analysis of an e-government project. Information Systems Journal, 16(1): 3-21.

Pitsis, T. S., Clegg, S. R., Marosszeky, M., \& Rura-Polley, T. 2003. Constructing the Olympic dream: A future perfect strategy of project management. Organization Science, 14(5): 574590.

Proffitt, W., \& Zahn, G. L. 2006. Design, but align: the role of organisational physical space, architecture and design in communicating organisational legitimacy. Advances in Organization Studies, 17: 204.

Rassin, E. 2007. A psychological theory of indecisiveness. Netherlands Journal of Psychology, 63(1): 1-11.

Ross, J., \& Staw, B. M. 1986. Expo 86: An escalation prototype. Administrative Science Quarterly: 274-297.

Ross, J., \& Staw, B. M. 1993. Organizational escalation and exit: Lessons from the Shoreham nuclear power plant. Academy of Management Journal, 36(4): 701-732. 
Selsky, J. W., \& Parker, B. 2005. Cross-sector partnerships to address social issues: Challenges to theory and practice. Journal of Management, 31(6): 849-873.

Sitkin, S. B., \& Pablo, A. L. 1992. Reconceptualizing the determinants of risk behavior. Academy of Management Review, 17(1): 9-38.

Sleesman, D. J., Conlon, D. E., McNamara, G., \& Miles, J. E. 2012. Cleaning up the big muddy: A meta-analytic review of the determinants of escalation of commitment. Academy of Management Journal, 55(3): 541-562.

Smith, W. K., \& Lewis, M. W. 2011. Toward a theory of paradox: A dynamic equilibrium model of organizing. Academy of Management Review, 36(2): 381-403.

Staw, B. M. 1976. Knee-deep in the big muddy: A study of escalating commitment to a chosen course of action. Organizational Behavior and Human Performance, 16(1): 27-44.

Steel, P. 2007. The nature of procrastination: A meta-analytic and theoretical review of quintessential self-regulatory failure. Psychological Bulletin, 133(1): 65-94.

Strauss, A., and J. Corbin. Basics of qualitative research techniques. Sage publications, 1998.

Tversky, A., \& Kahneman, D. 1981. The framing of decisions and the psychology of choice. Science: $453-458$.

Van Marrewijk, A., Clegg, S. R., Pitsis, T. S., \& Veenswijk, M. 2008. Managing public-private megaprojects: Paradoxes, complexity, and project design. International Journal of Project Management, 26(6): 591-600.

Waddock, S. A. 1989. Understanding social partnerships an evolutionary model of partnership organizations. Administration \& Society, 21(1): 78-100.

Westley, F., \& Vredenburg, H. 1997. Interorganizational collaboration and the preservation of global biodiversity. Organization Science, 8(4), 381-403. 
Table 1. Data sources, including details on informants by organization

\begin{tabular}{|c|c|c|}
\hline Source & Amount & Details \\
\hline $\begin{array}{l}\text { Semi- } \\
\text { structured } \\
\text { interviews }\end{array}$ & $\begin{array}{l}\text { Total number: } 42 \text {, fully } \\
\text { recorded-fully } \\
\text { transcribed with } 35 \\
\text { informants } \\
\text { Average length: } 100 \\
\text { minutes }\end{array}$ & 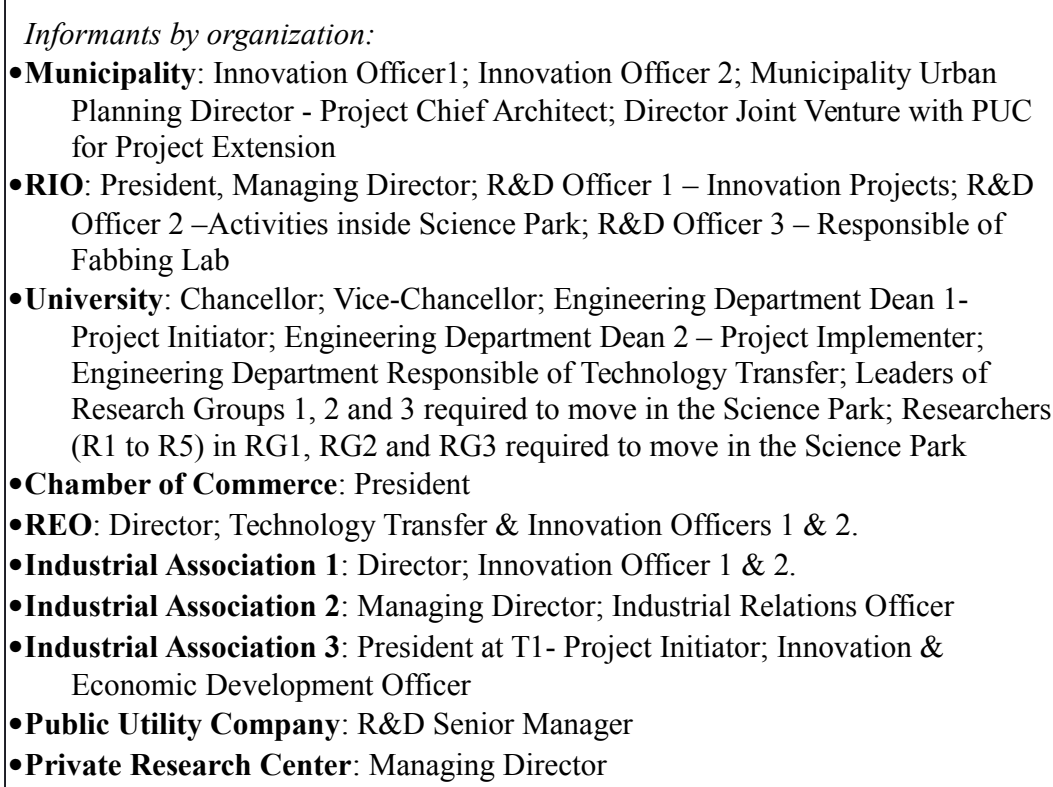 \\
\hline $\begin{array}{l}\text { Participant } \\
\text { observations }\end{array}$ & $\begin{array}{l}\text { Total number: } 26 \\
\text { Timespan: } 2014 \text { - } 2016\end{array}$ & $\begin{array}{l}\text { Type of participated events: } \\
10 \text { Board of Directors meetings } \\
3 \text { Shareholder meetings } \\
2 \text { conferences } \\
2 \text { public events } \\
9 \text { meetings between partner organizations }\end{array}$ \\
\hline Archival data & $\begin{array}{l}\text { Total number: } \\
269 \text { official documents } \\
\text { and press articles } \\
\text { Timespan: } 2009 \text { - } 2016\end{array}$ & $\begin{array}{l}\text { Types of documents: } \\
200 \text { press articles about the science park project } \\
8 \text { documents about science park project posted on websites } \\
13 \text { internal documents of partner organizations (e.g., reports, budgets) } \\
2 \text { protocols regulating the partnership } \\
6 \text { public announcements and calls for funding } \\
10 \text { brochures of the activities of the partners } \\
15 \text { brochures of the events and activities of the science park } \\
2 \text { architectural projects } \\
10 \text { promotional videos } \\
3 \text { construction site plans }\end{array}$ \\
\hline
\end{tabular}


Table 2. Representative examples of partners' collaboration promises and associated sub-coalitions in the early phase of the partnership (science park focus) and during the development of the partnership (innovation multiplex focus)

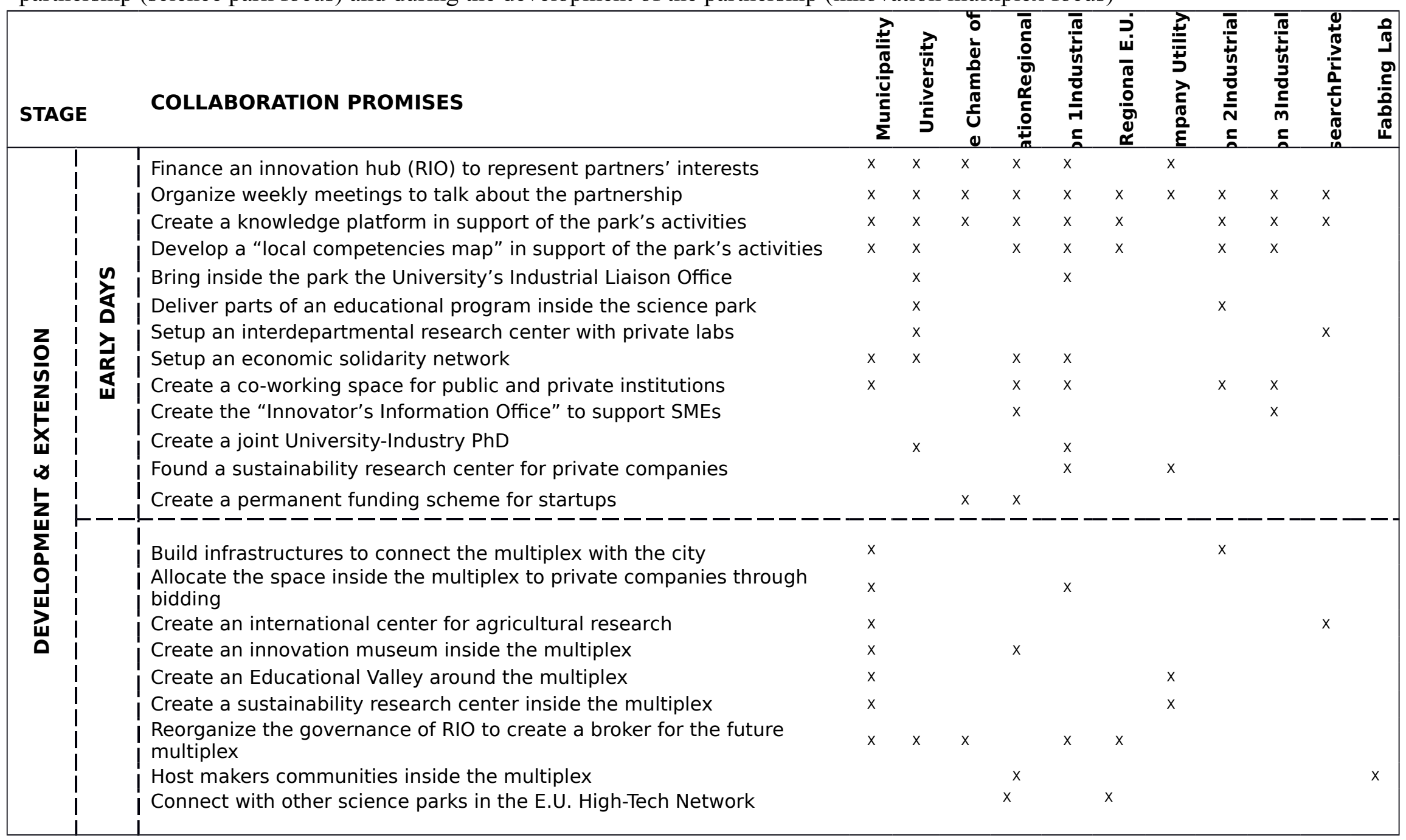


Figure 1: A grounded model of vicious circles of decision in hybrid collaborations

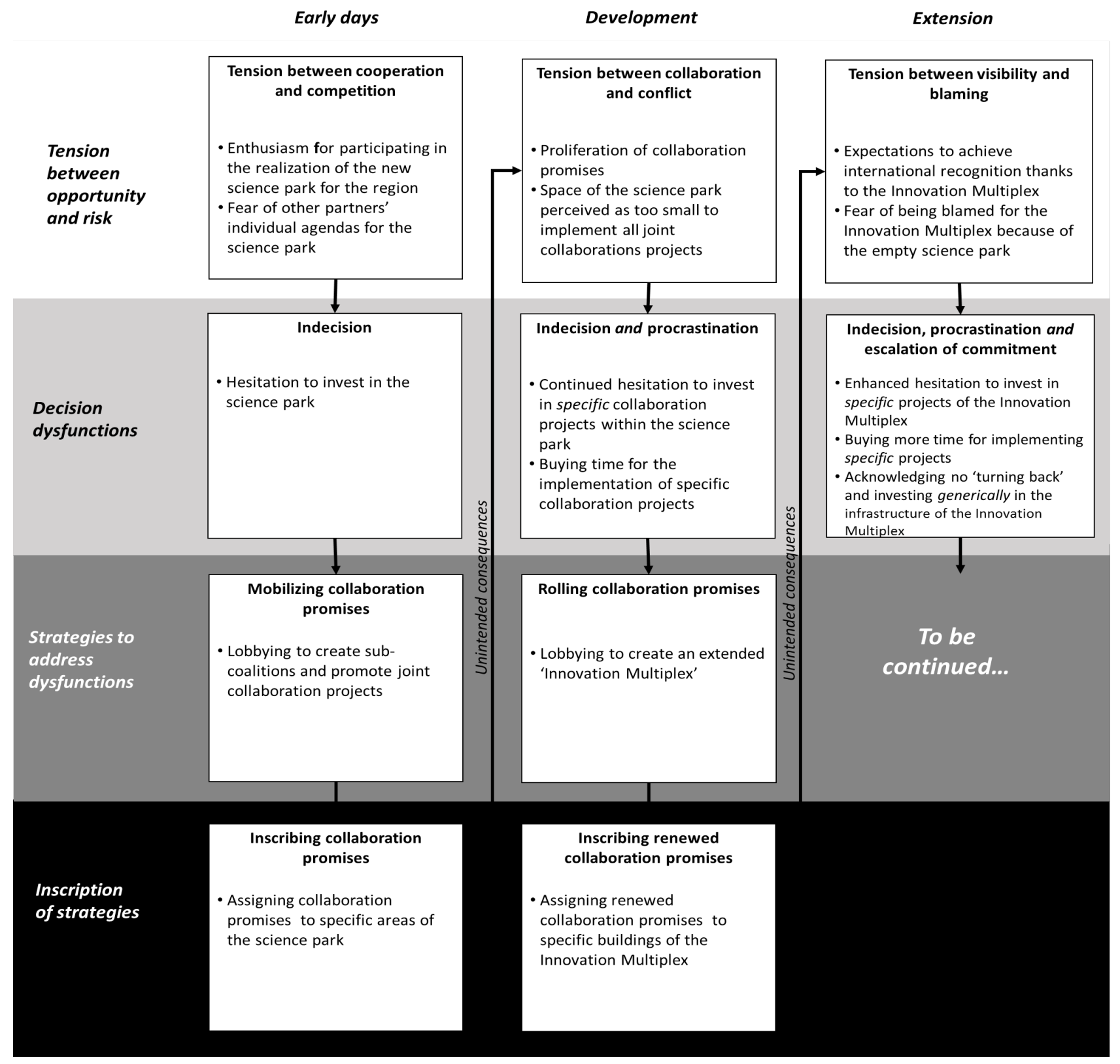


Figure 2. Formal model of vicious circles of decision in hybrid partnerships

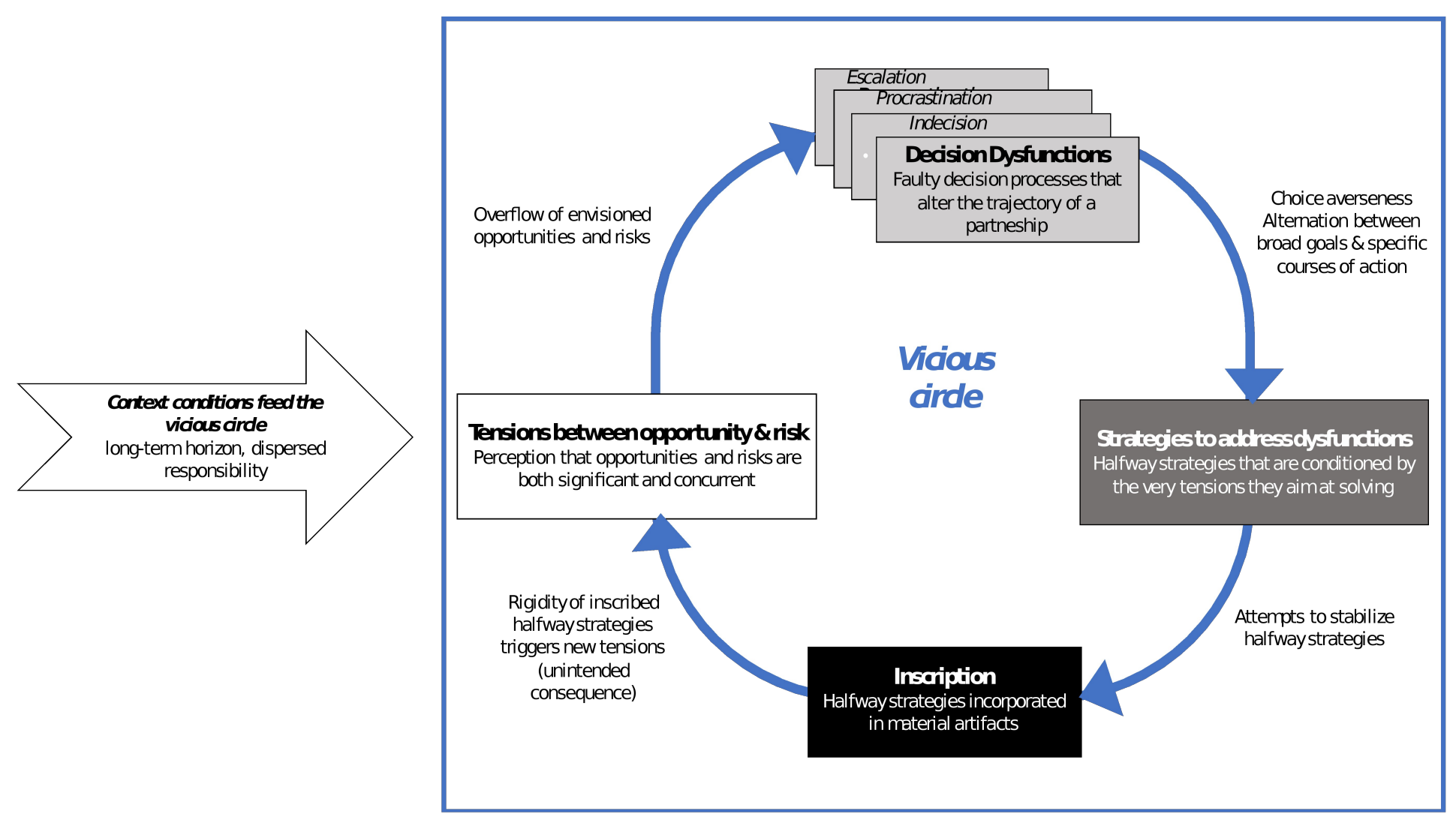

Intention to exit from viciaus cirde The intended consequence of The intended consequence of
strategies and their inscription is to overcome risk-opportunity tensions 
Appendix 1: Timeline of the evolution of the hybrid partnership lifecycle.

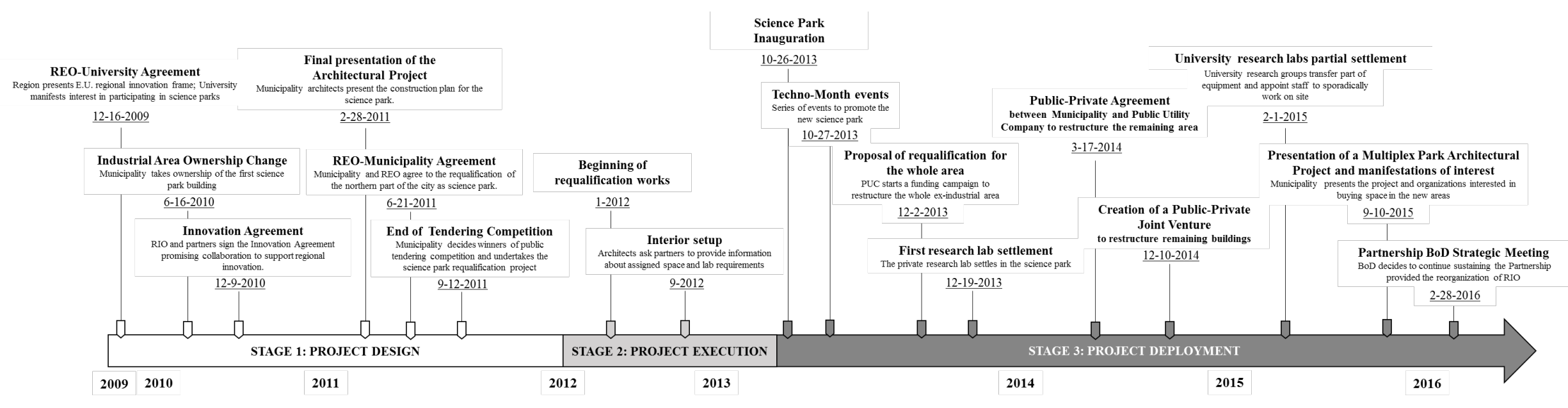


Enthusiasm for participating in the realization of the new regional science park e.g. Partners describing the partnerships as a way to promote social and economic growth in the region through open innovation

e.g. Partners expressing their desire to create new synergies with other players in the region e.g. Partners describing collective goal regarding open innovation and technological transfer Fear of partners' individual agendas for the science park

e.g. Industrial Association 2 expressing fear for overlaps with Industrial Association 1's agenda

e.g. Industrial Association 1 describing the risks of having different organizational goals among the partners

e.g. RIO describing its difficulties as mediator ofdifferent organizational interests

e.g. University acknowledging difficulties in accomodating the urban planning projects of the Municipality

\section{Proliferation of collaboration promises}

e.g. Municipality architects designing spaces to encourage people to meet

e.g. Partners see park's coworking space as opportunity to collaborate with other partners e.g. Partners describing the park as opportunity to connect with other innovation hubs Space of the science park perceived as too small to implement all collaboration projects e.g. Partners lamenting that rooms are vacant

e.g. Partners describing the coworking area as insufficient to accomodate all partners e.g. Partners lamenting the science park cannot accomodate new stakeholders (IP specialists, makers, E.U. funding experts, interested private firms)

Expectations to achieve international recognition thanks to the Innovation Multiplex e.g. Partners (Municipality, University, CoC, Private Research Lab) acknowledging the innovation multiplex as a showcase at the national and international scale

e.g. Industrial Associations aiming to increase the visibility of their members nationally e.g. University wishing to improve its image with citizens, government and private firms e.g. RIO wishing to gain partners' (esp. Municipality, Chamber of Commerce and Ind. Ass) legitimation by planning the future activities of the innovation multiplex

Fear of being blamed for Innovation Multiplex because of the enpty science park e.g. Partners expressing fear that the empty park communicated failure

e.g. RIO expressing fear of being blamed for lack of activities in the science park and losing credibility as broker of the innovation multiplex

e.g. University, PUC, Ind Ass $1 \& 2$ acknowledging the risk of Innovation Multiplex failure

\section{Indecision about science park investments}

e.g. Municipality, CoC, University \& PRL hesitating to allocate resources to science park e.g. Partners manifesting difficulties in doing things together

e.g. Ind Ass 1, 2, 3, PUC, CoC hesitating to give information about their use of the park

e.g. Partners describing different and contrasting views of the park

e.g. Partners showing difficulties in identifying the park's governance

Continued hesitation to invest in specific collaboration projects within the science park e.g. University, RIO, Ass Ind 1,2,3 hesitating to transfer in the common spaces inside the park e.g. University waiting for European funds before transfering their activities inside the park Buving time for the inplementation of specific collaboration projects

e.g. Partners postponing in the future plenary meetings about space allocation

e.g. Ind Ass 1, Municipality manifesting doubts about spending money in collaboration promises and manifetsing intention to wait for less risky conditions

\section{Showing inabilitv or hesitation to make decisions in the presence of multiple goals} \& Postponing decisions about implementation of collaboration promises $\underline{\boldsymbol{\varepsilon} \text { Investing new resources to sustain or add collaboration promises }}$

e.g. Partners continuing to sponsor the infrastructure of the innovation multiplex e.g. Partners postponing the evaluation of project results

e.g. Partners waiting for the expansion of the park to invest in collaboration promises e.g. Partners hesitating to assess the failure of previous plans before starting new ones

\begin{tabular}{|l|}
\hline Lobbving to create sub-coalitions and promote ioint collaboration projects \\
e.g. RIO framing the park as opportunity for each partner to develop one's projects \\
e.g. Municipality framing park building as ownership of University, private firms and citizens \\
e.g. Municipality drafting new educational programs with University to be carried out inside \\
the park \\
e.g. RIO and Ind. Ass 1 making plans for the allocation of coworking spaces
\end{tabular}

e.g. RIO and Ind. Ass 1 making plans for the allocation of coworking spaces

\section{Lobbving to create an extended 'innovation multiplex'}

e.g. Partners proposing to extend the area of the park, creating an innovation multiplex e.g. RIO \& Ind. Ass1, 2 proposing to enlarge the coworking space to get everybody in e.g. Partners promising to move in the park once the innovation multiplex is completed e.g. Municipality proposing to organize events to promote the innovation multiplex e.g. Partners trying to convince each other of new initiatives for the innovation multiplex

\footnotetext{
e.g. Partners describing the science park as the 'home' for strategic relationships e.g. Partners assigning rooms of the science park to specific projects (coworking space, incubator, dirigible, industrial liaison office, EU directline, innovator's office, etc.) e.g. Partners describing the science park as the place where innovation can be «seen with one's eyes» and «touched with one's hands»

e.g. Partners describing the physical features of the science park (e.g. open, without separations) as facilitators of partners' specific projects

e.g. Municipality making sure the bulding evokes open innovation and collaborative spirit

e.g. Municipality's architect creates a physical model of the new innovation multiplex e.g. Partners drafting new organizational goals in buildings 18 and 19 of the multiplex e.g. Partners describing the innovation multiplex as the 'home' of the most innovative activities

e.g. Partners relaunching collaboration projects to be carried out inside the multiplex e.g. Partners refferring to the extended area of the multiplex as an extension of their specific collaboration projects
}

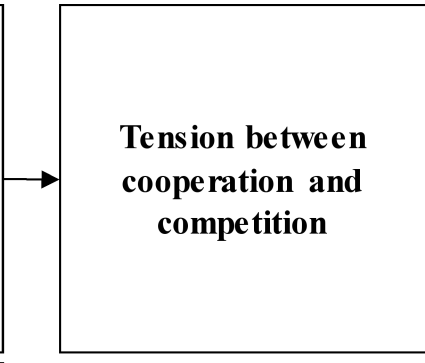

Tension between collaboration and conflict

Tension between visibility and blame
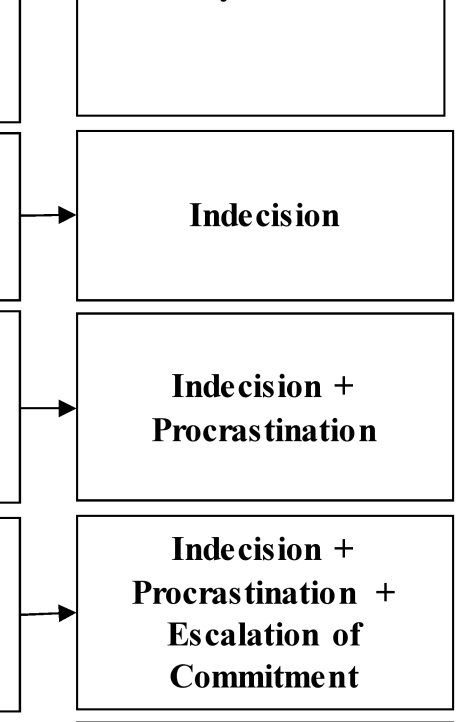

$\rightarrow \begin{gathered}\text { Mobilizing } \\ \text { collaboration } \\ \text { promises }\end{gathered}$

$\rightarrow$\begin{tabular}{c|} 
Rolling \\
collaboration \\
promises
\end{tabular}

\section{Ins cribing collaboration promises}

Inscribing renewed collaboration promises
Tension between risk and opportunity
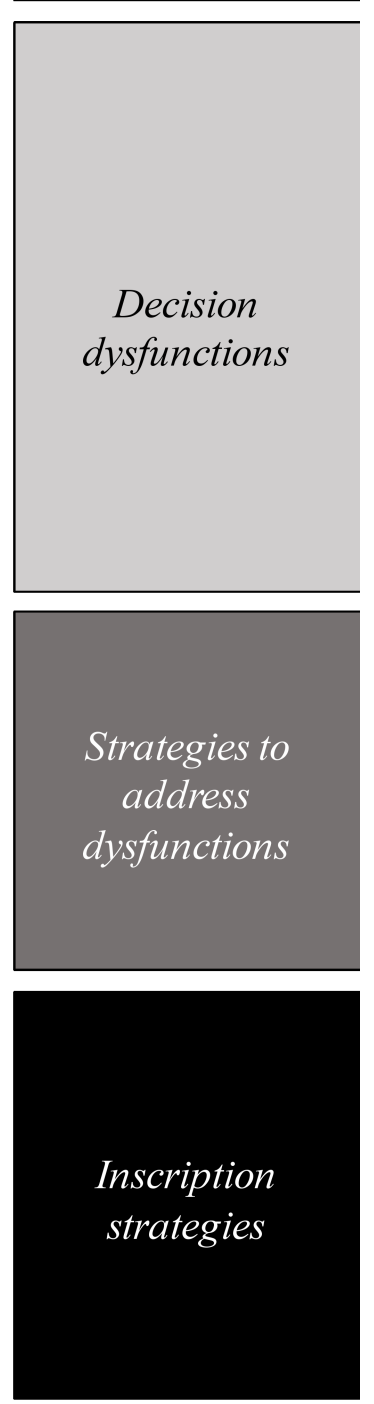